\title{
Aportación al estudio de la significación del adjetivo: el modo y la gradación
}

\author{
ANTONIA M. ํㅡㄹ.ZQUEZ LEÓN \\ Facultad de Filosofia y Letras
}

1. En esta exposición se va a intentar estudiar el adjetivo desde el punto de vista significativo, principalmente, pero, sobre todo, limitándonos a señalar que, aunque significa esencialmente modo, no obstante, posee un morfema (diferenciador) de grado que es, a veces, interpretado como comparativo. Ciertamente, el adjetivo es un elemento oracional que puede expresar modo y más que comparación se cree que gradación y ésta, a su vez, no podemos entenderla como lo hacen gran parte de nuestras gramáticas, que toman como punto de partida la lengua latina, porque, como es sabido, no podemos mantener los esquemas latinos para estudiar la estructura y el funcionamiento de nuestra lengua.

Para ello, vamos a tratar el adjetivo desde los criterios definitorios hasta sus valores funcionales y significativos.

2.0. Hasta los primeros años del $S$. XX el adjetivo suele ser definido según un criterio semántico. A partir de este siglo se produce un cambio que se manifiesta por la definición del adjetivo sobre la base de un criterio sintáctico colocacional y lo semántico pasa a un segundo lugar.

María Luisa Calero afirma que:

"Las descripciones del adjetivo responden ahora al siguiente esquema:

$1^{\circ}$ acompaña (o se junta, o se une) al sustantivo

$2^{\circ}$ para calificarlo o determinarlo o para expresar sus cualidades) ${ }^{\prime \prime}$.

Entre los que caracterizan asi al adjetivo señala a Sánchez Doblas, Navarro, y la G.R.A.E. $(1870,1920)$ entre otros. Sin embargo, denuncia que definan al sustantivo desde

\footnotetext{
'M." Luisa CALERO VAQUERA, Historia de la gramática Española, Madrid, Gredos, 1986, pág. 76.
} 
una perspectiva extraoracional y, posteriormente, tratan el adjetivo desde otra, intraoracional, en la que se toma el sustantivo como punto de referencia.

Termina citando tres autores, Bello, Nonell y Lenz, que son más consecuentes con su sistema y sus principios linguisticos y se sirven del mismo criterio sintáctico para definir tanto al sustantivo como al adjetivo.

\subsubsection{Estudio de la función del adjetivo.}

Desde el punto de vista de la función, el adjetivo es definido como término secundario dependiente del sustantivo, que es el único término primario. La función del adjetivo es la de precisar o ampliar la significación del sustantivo.

Antes de proseguir, es conveniente hacer una clasificación de los adjetivos. Se pueden clasificar teniendo en cuenta su significación, la función y la referencia. La clasificación semántica es la que hace Mabel Manacorda Rossetti, en la línea de Amado Alonso y Ana Maria Barrenechea. Clasifica los adjetivos por su significación en connotativos y no connotativos y aquéllos a su vez en actualizadores y no actualizadores. Los calificativos, con marca de concordancia o sin ella, pertenecerian a los connotativos no actualizadores.

En la clasificación de los adjetivos por su cambio de clase o función los agrupa en cuatro clases: los que pasan a adverbios sin cambio formal, que son los connotativos no actualizadores; los que pasan a sustantivos sin cambio formal; los que pasan a sustantivo con posibilidad de cambio formal y, finalmente, los que pasan a adverbios con cambio formal.

La tercera forma de clasificar a los adjetivos es por su referencia. Ésta puede ser directa (atributos) e indirecta (predicativos).

Ésta es la clasificación que se seguirá en el tratamiento del adjetivo.

\subsubsection{Adjetivo incidente en un nombre.}

Como ya se dijo, el adjetivo es dependiente del sustantivo. Esta dependencia se marca en la función por medio de una referencia como acabamos de decir. En español, el adjetivo atributivo tiene libertad de colocación en la frase. Las posibilidades son: especificativo, que va normalmente pospuesto al nombre y suele limitar, aunque no siempre, la extensión significativa del sustantivo que le precede. Puede ir también antepuesto y modificar el contenido semántico de éste insistiendo en sus notas. La anteposición suele revelar un propósito estilístico.

El adjetivo atributivo explicativo es de colocación más flexible: puede ir inmediatamente delante; detrás, entre pausas, o delante, con pausa, si el nombre lleva determinante:

El acelerado alumno $\longrightarrow$ El alumno, acelerado, $\longrightarrow$ contestó
Acelerado, el alumno $\longrightarrow$

En cuanto a la terminologia que se utiliza, hay que señalar que se sigue la centroeupea, 
adoptada también por Pottier.

Por último hay un grupo bastante numeroso de sintagmas en los que el orden es invariable. Si se altera éste se rompe la unidad semántica, tal es el caso de las locuciones modales como a ciencia cierta, etc.

Cuando el adjetivo se refiere al sustantivo a través de un indice verbal, se denomina adjetivo predicativo:

El alumno está acelerado.

\subsubsection{Adjetivo incidente en un verbo:}

Además de estas dos clases de adjetivos, atributivos y predicativos, hay otras clases de adjetivos relacionados con el verbo: el adjetivo atributivo adverbial y el adjetivo adverbial. El primero modifica al mismo tiempo sustantivo y verbo. Por ser esta función propia de un adverbio se habla también de adverbialización del adjetivo:

Alfanhuí los miraba silencioso.

(Sánchez Ferlosio, Alfanhuí, p. 45)

que puede presentarse de la siguiente manera:

Alfanhuí los miraba silenciosamente

El adjetivo es fácilmente sustituible por un adverbio: silenciosamente.

La otra clase de adjetivo relacionado con el verbo es el adjetivo adverbial que funciona como modificador del verbo sin referencia al sustantivo. La referencia al sustantivo es inexistente, hasta el punto de no haber concordancia:

Las palomas volaban alto.

Al adjetivo atributivo adverbial se le han dedicado recientemente varias estudios como los de Josefina Martinez Álvarez ${ }^{2}$, Bonifacio Rodríguez ${ }^{3}$, José Andrés de Molina ${ }^{4}$, Violeta Demonte ${ }^{5}$, Otto Prytz ${ }^{6}$, etc.

2 Josefina MARTiNEZ ÁlvAREZ, "El atributo y sus variedades en español", en Momenaje a Alonso Zamora Vicente, I. (Historia de la Lengua Española: el español contemporáneo. Madrid, Castalia, 1988,
págs. 451-457.

. "Sobre algunas estructuras atributivas", en Lecciones I y I/ Curso de Linguistica funcional, (1983 y 1984), Universidad de Oviedo, Servicio de Publicaciones, págs. 11-119.

3 Bonifacio RODRIGUEZ DÍEZ, "L'attribut en espagnol", La linguistique, 18.2, 1982, pág. 39.

* José Andrés DE MOLINA REDONDO Y ORTEGA, J.: Usos de ser y estar. Madrid, 1987.

s Violeta DEMONTE, "Semántica y sintaxis de las construcciones con 'ser' $y$ 'estar', R.S.E.L., IX/1, 1979, págs, 133-171.

${ }^{6}$ Otto FRYTZ, "Situación del predicativo en espanol", Revue Romane, 1979, Copenhague, págs. 81-81. 
Josefina Martínez $z^{7}$ estudia este tipo de estructuras atributivas y distingue tres grupos: Un primer grupo en que los adjetivos concuerdan en número con el sujeto gramatical del núcleo, y en número y género con el sujeto léxico. Funcionan a la manera de los atributos, pero si se eludieran no serían representables por la forma $/ \mathrm{lo}$, al igual que los verdaderos atributos. Además estos adjetivos serian fácilmente sustituibles por un adverbio. Lo ejemplifica de la siguiente manera:

El abogado vivía tranquilo.

El abogado vivia tranquilamente.

Alarcos propone $e^{8}$, dice Josefina Martinez, para estas unidades el término de aditamento atributivo. Otros autores lo denominan predicatoide o, como hace Prytz, predicativo adverbial. Considera acertado el criterio de Bonifacio Rodriguez al señalar que este tipo de atributo también es compatible con núcleos verbales que lleven suplemento o implemento, donde, además, la unidad atributiva podria aparecer en aposición con el término a que se refiere: los espectadores, entusiasmados, hablan del partido.

Distingue un segundo grupo en el que existe un implemento junto al núcleo verbal. Si dicho implemento se elude dejaria un incremento pronominal en el verbo aludiendo a su función y señalando el morfema de género y número del sintagma eliminado: la eligieron reina. En este caso, reina, que funciona como atributo varía en sus morfemas de género y número de acuerdo con los que lleve el implemento. Hay un comportamiento paralelo al de las estructuras propiamente atributivas, pero en este caso no se puede hablar de atributo porque, dice Josefina Martínez, la concordancia reúne este sintagma y el que actúa como implemento. Por ello, dice, a diferencia del atributo propio, estas otras unidades no dejan como referente, al eludirse, el invariable $l o$, sino un adverbio igual que en los ejemplos del primer grupo, o, en los casos del sintagma sustantivo, un referente demostrativo neutro. Eligieron eso a su hijo. Hecho que Josefina Martínez declara como ya apuntado por J.A. Martinez y Bonifacio Rodríguez.

Finalmente, señala un tercer grupo de ejemplos que presentan todos incrementación reflexiva del sintagma verbal. Serían análogas otras oraciones, dice, con sujeto gramatical de primera o segunda persona.

Mi hijo se casó joven.

Yo me casé joven.

En todos los casos expuestos, el adjetivo, como es sabido, añade una nota modal. Se trata pues de una forma de expresar el modo.

\subsection{La gradación adjetiva.}

Desde el punto de vista de la forma los adjetivos se componen de lexema y formantes

7 Josefina MARTÍNEZ, "El atributo y sus variedades...", cit. págs. 451.454.

${ }^{8}$ Emilio ALARCOS, Estudios de gramática funcional del español, 3. a ed. Madrid, 1980, págs. 159-160. 
como los sustantivos. Los formantes son los mismos que los del sustantivo, pero hay que añadir el morfema de grado que el sustantivo no tiene.

Los formantes del adjetivo dependen del sustantivo y están obligados a concordar. Por otra parte, todo sustantivo lleva consigo un género, el adjetivo no. El género del sustantivo impone el del adjetivo. El número del adjetivo ha de ser también el mismo del sustantivo del que depende. El adjetivo es pues, incidente al sustantivo y, por tanto, dependiente de él.

El formante de número tiene en los adjetivos los signos externos del plural (-s-es) en todos los casos. Por el contrario, el morfema de género puede presentarse de dos maneras: con marca de concordancia (o/-a), o sin marca de concordancia.

En cuanto al grado, este formante tiene un doble aspecto, morfológico y sintáctico.

La gradación morfemática es aquélla que utiliza marcas y derivativos por las que el adjetivo adquiere un grado superior: conocido, conocidisimo, archiconocidisimo. Son formas de superlativo absoluto que se crean bien por medio del superlativo culto en -isimo o- érrimo, o por superlativos coloquiales por prefijación de ultra, = super, re-, archi- y formas reforzadas como reque-, requete-

Además, hay que añadir los escasos restos latinos, muchos de los cuales han perdido su valor de grado:

Bueno, mejor, óptimo. Malo, peor, pesimo. Grande, mayor, máximo. Pequeño, menor, minimo.

La gradación sintáctica, por el contrario, acude a la asociación sintagmática con segmentos terciarios: muy conocido; más conocido.

En todos estos casos la gradación no debe confundirse con la comparación aunque, a veces, ésta estè implicita:

Este libro es más conocido (que aquél).

Este libro es mejor (que aquél).

Rodolfo Lenz en un apartado dedicado a la gradación relativa y a la comparación, dice:

"Es un hecho conocido que en las lenguas indoeuropeas los adjetivos en general presentan una variación formal con terminaciones, por medio de las cuales se derivan de las formas primitivas, en este sentido llamadas $<<$ positivas $>>$, dos grupos de formas que se llaman $<<$ comparativas $>>\mathrm{y}<<$ superlativas $>>$ " .

Señala posteriormente como en todas las gramáticas se suele explicar que el adjetivo, en forma primitiva o positiva expresa cualidad, modo: el niño está bueno; este mismo adjetivo puede expresar también comparación por medio de un sufijo o de un adverbio antepuesto que expresa intensidad:

el niño está mejor.

el niño está más cómodo.

${ }^{9}$ Rodolfo LENZ, La oración y sus partes, 3. ed., Madrid, Centro de Estudios Históricos, 1935, pág. 185. 
Lenz, más adelante, cree conveniente aclarar y hacer algunas observaciones respecto al término "gradación": dice:

"Casi todas las gramáticas castellanas que conozco hablan de la $<<$ comparación de los adjetivos $>>$. Hay en esto el grave inconveniente de que, en efecto, no son los adjetivos los que se comparan, sino los sustantivos. Los adjetivos tienen, formas para diferentes grados de la cualidad; de consiguiente, su variación formal merece más bien el nombre de gradación. Así denomina el señor Menéndez Pidal en su manual (379), y lo seguiré en adelante, reservando la palabra <<comparación $>>$ para el acto mental de comparar un objeto con otro" ${ }^{10}$.

Compartimos este criterio, y pensamos con Lenz que 'los adjetivos tienen formas para diferentes grados de la cualidad', es decir, que los adjetivos expresan grados de significación. Esta gradación puede ser positiva y superlativa, como se dijo anteriormente.

\section{Conclusiones.}

Podemos concluir diciendo que el adjetivo expresa modo y gradación. Respecto a ésta, siguiendo la terminología de Dauzat ${ }^{\prime \prime}$, hay que identificarla con la gradación intensiva-o grados absolutos de Brunot-que no están limitados al superlativo absoluto, sino que comprende todos los grados intermedios entre el cero y el infinito linguístico. Estos intermedios se expresan por los procedimientos más diversos: cambio de epiteto y, sobre todo, por adición de partícula (poco, bastante, mucho, etc.).

Alcina y Blecua ${ }^{12}$ prefieren emplear el término 'gradación' por ser más aplicable al adjetivo (calificativo), como nombres de cualidades y por ello admiten grados de significación. Esta cualidad podría darse en cantidad y proporción variables que irán de mayor a menor o a la inversa. En estas oscilaciones son discernibles grados de atribución o significación que pueden conseguirse por medios léxicos, morfológicos, sintácticos y prosódicos.

${ }^{10}$ Idem, págs. 184-185.

"Albert DAUZAT, "L'expression de i'intensité par la comparaison" dans Le francais moderne, XIII, 1945, pág. 169-170.

12 Juan ALCINA y José Manuel BLÉCUA, Gramática española, Madrid, Ariel, 1975, pág. 573 y ss. 